\title{
Electroörganic Preparations
}

\section{Reduction of Methylanthranil and o-Aminoacetophenone}

\author{
HENNING LUND and AGNETE D. THOMSEN
}

Department of Organic Chemistry, University of Aarhus DK-8000 Arhus C, Denmark

\begin{abstract}
Methylanthranil can be reduced to $o$-aminoacetophenone in acid solution. This compound produces on reduction a mixture of compounds; the composition of the mixture is dependent on $\mathrm{pH}$. Besides the expected alcohol and the meso- and D,L-pinacols are in alkaline solution isolated two compounds with the same empirical formula as the pinacols. They are shown to be stereoisomers of 3-acetyl-4amino-7-hydroxy-7-methyl-2,6-methano-2,5,6,7-tetrahydro-1(1 H)benzazonine. The mechanism of the electrolytic reaction is discussed.
\end{abstract}

In connection with a polarographic investigation of anthranils the electro1 chemical behaviour of $o$-aminoacetophenone (I) was studied, as this compound was found to be an intermediate in the reduction of 3-methylanthranil (II). o-Aminoacetophenone was investigated by means of polarography and controlled potential electrolysis, and the dependence of the product distribution on $\mathrm{pH}$ was studied.

\section{POLAROGRAPHIC INVESTIGATION}

In Fig. 1 are shown the half-wave potentials and limiting currents of 3methylanthranil in dependence on $\mathrm{pH}$, and in Fig. 2 the corresponding data for $o$-aminoacetophenone are depicted.

The second wave of II is in acid solution found at the same potentials as those of I suggesting that II is reduced to I which then is further reducible. Controlled potential electrolysis of II confirms that the electrode reaction corresponding to its first wave is

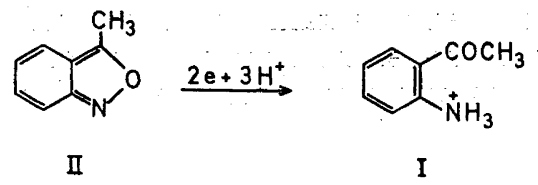

Acta Chem. Scand. 23 (1969) No. 10 


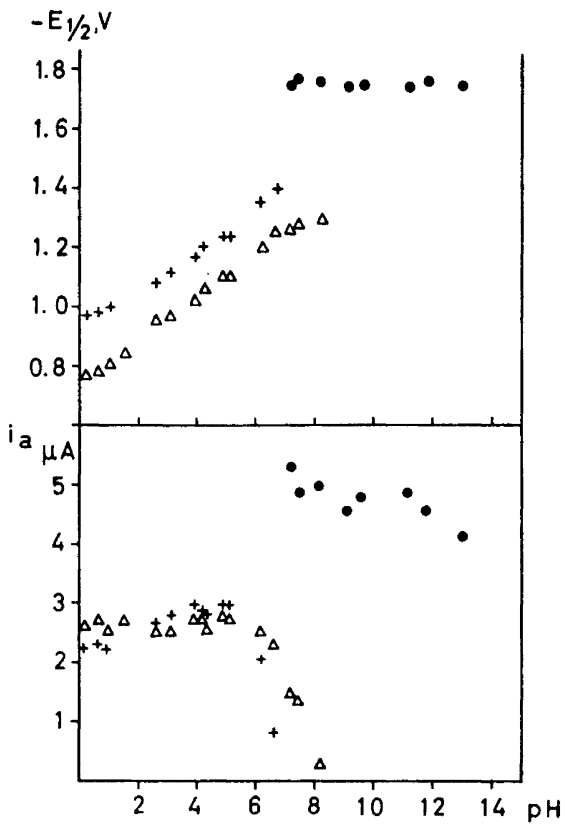

Fig. 1. Limiting currents $(\mu \mathrm{A})$ and half. wave potentials (vs. SCE) of 3-methylanthranil in $40 \%$ aqueous ethanol. Concentration $80 \mathrm{mg} / \mathrm{l} . \triangle$, + data of 1 . and 2 . wave in acid solution, respectively. data of wave in alkaline solution.

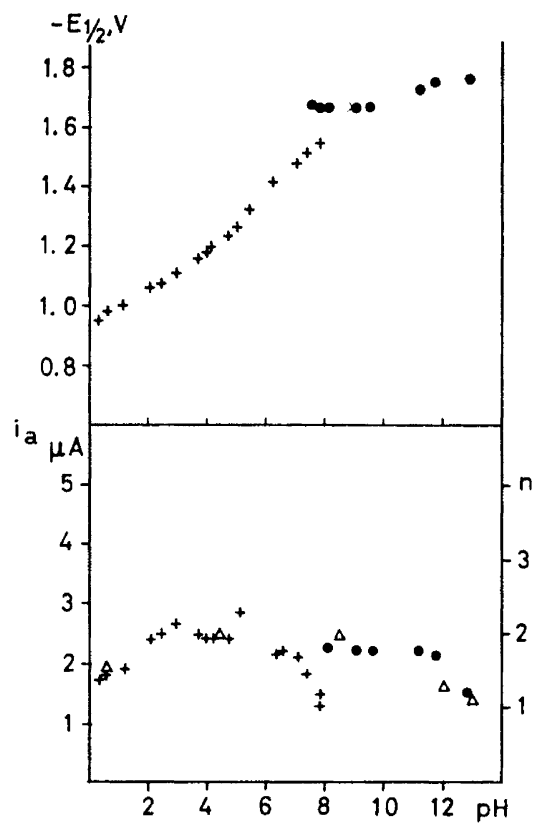

Fig. 2. Limiting currents $(\mu \mathrm{A})$ and halfwave potentials ( $v s$. SCE) of o-aminoacetophenone in $40 \%$ aqueous ethanol. Concentration $80 \mathrm{mg} / \mathrm{l}$, +, data of waves in acid and alkaline medium, respectively. $\triangle n(\mathrm{~F} / \mathrm{mole})$ from the preparative reductions.

The hydrogenation of the oxygen-nitrogen bond is analogous to that found in the reduction of oximes ${ }^{1}$ and other derivatives of hydroxylamine in acid solution.

The reduction of II in alkaline solution occurs at a slightly more negative potential than that of $I$ and a reduction of II to $I$ is not possible, but results in a further reduction of the intermediately formed I, which is discussed below.

The dependence of the limiting current of $\mathrm{I}$ on $\mathrm{pH}$ is similar to that found for acetophenone by Elving and Leone. ${ }^{2}$ In Fig. 2 is as ordinate also shown $n$ (number of electrons in the electrode reaction) assuming that the limiting current at $\mathrm{pH} 4$ corresponds to $n=2$. The small difference in diffusion coefficient between the protonated form reduced in acid solution $(\mathrm{pH}<7)$ and the neutral molecule reduced in alkaline solution $(\mathrm{pH}>8)$ is neglected. The $n$-values from the preparative electrolysis are also given in Fig. 2; the agreement between the polarographic and preparative data is satisfactory. 
Fig. 3. Half-wave potentials (vs. SCE) of III (upper figure) and IV (lower figure) in $40 \%$ aqueous ethanol. $\Delta,+$ data of 1 . and 2. wave, respectively.

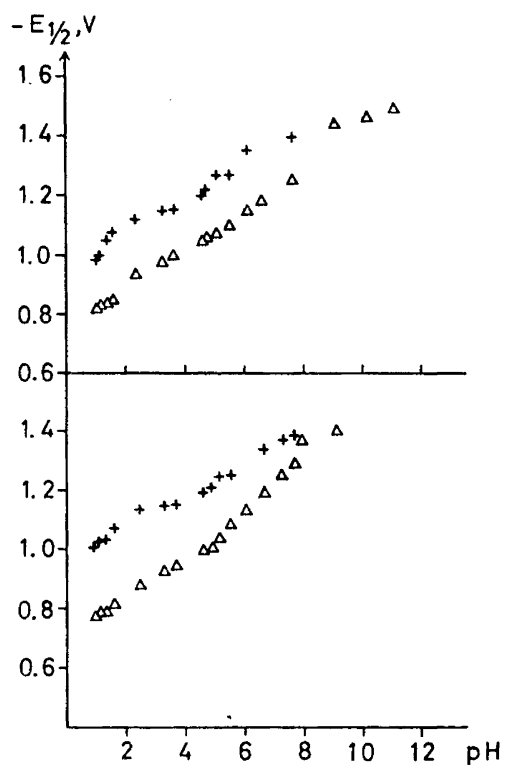

In Fig. 3 are depicted the half-wave potentials of two of the reduction products, III and IV, isolated from the reduction of I in alkaline solution. Neither III nor IV is reducible in basic medium.

\section{PREPARATIVE REDUCTION}

Reduction of $o$-aminoacetophenone gives several products among which are identified 1-(2'-aminophenyl)ethanol (V), the two pinacols VI (m.p. $183^{\circ}$ ) and VII (m.p. 134-136 ), and two compounds III (m.p. 196 $6^{\circ}$ ) and IV (m.p. $165-167^{\circ}$ ), which from the available evidence are believed to be stereoisomers of 3-acetyl-4-amino-7-hydroxy-7-methyl-2,6-methano-2,5,6,7-tetrahydro- $1(1 \mathrm{H})$-benzazonine. Besides these products traces of $4-5$ compounds have been detected in the reduction mixture in slightly acid solution by TLC.<smiles>CCc1ccccc1N</smiles>

$\mathbf{Y}$<smiles>CC(O)(c1ccccc1N)C(C)(O)c1ccccc1N</smiles>

DI III

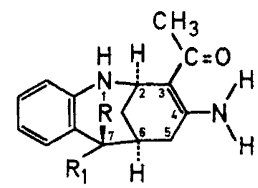

III $\mathrm{R}=\mathrm{OH} \quad \mathrm{R}_{1}=\mathrm{CH}_{3}$

II $\mathrm{R}=\mathrm{CH}_{3} \quad \mathrm{R}_{1}=\mathrm{OH}$

In Table 1 is given the composition of the reaction mixtures at different $\mathrm{pH}$ from the electrolytic reduction of $o$-aminoacetophenone in a medium Acta Chem. Scand. 23 (1969) No. 10 
Table 1. Composition (in \%) of the reaction mixtures from the electrolytic reductions of $o$-aminoacetophenone at different $\mathrm{pH}$ determined by NMR-spectroscopy. The percentages in brackets in the last column refer to isolated yields.

\begin{tabular}{|c|c|c|c|c|c|}
\hline $\begin{array}{c}\mathrm{pH} \\
\text { Buffer }\end{array}$ & $\begin{array}{c}1.5 \\
0.5 \mathrm{~N} \mathrm{HCl}\end{array}$ & $\begin{array}{c}4.5 \\
\text { Acetate }\end{array}$ & $\begin{array}{c}8.5 \\
\text { Phosphate }\end{array}$ & $\begin{array}{c}12 \\
\text { Phosphate }\end{array}$ & $0.1 \stackrel{13}{\mathrm{M}} \mathrm{KOH}$ \\
\hline$-E(\mathrm{~V} v s . \mathrm{SCE})$ & 1.20 & 1.38 & 1.42 & 1.75 & 1.85 \\
\hline$n$ (exptl.) & 1.56 & 2.0 & 2.0 & 1.25 & 1.17 \\
\hline$n(\text { calc. })^{a}$ & 1.51 & $2.0^{b}$ & 2.0 & 1.34 & 1.12 \\
\hline \multicolumn{6}{|l|}{ Compounds (yield \%) } \\
\hline III "benzazonine" & - & -- & 一 & 18 & $23(23)$ \\
\hline IV "benzazonine" & - & - & $\ldots$ & 18 & $35(29)$ \\
\hline V “alcohol”' & 38 & 73 & $>98$ & 34 & $8 \quad(6)$ \\
\hline VI "pinacol m.p. $183^{\circ}$ & 29 & 2 & - & 18 & $21(20)$ \\
\hline VII "pinacol m.p. $135^{\circ "}$ & 25 & trace & - & 12 & $9 \quad(9)$ \\
\hline Unidentified & 8 & $25^{c}$ & - & - & $4 \quad(4)$ \\
\hline VI/VII & 1.14 & - & - & 1.5 & 2.5 \\
\hline
\end{tabular}

a Calculated from the product distribution.

$b$ The unidentified products are assumed to consuine $2 \mathrm{~F} /$ mole.

$c$ A mixture of at least four products different from $\mathrm{I}-\mathrm{VII}$.

containing $20 \%$ ethanol. The yields are determined from the crude reaction mixture by NMR-spectroscopy; the results thus obtained in alkaline solution were checked by separation and isolation of the compounds by column chromatography.

Whereas the formation of $\mathrm{V}$ requires $2 \mathrm{~F} / \mathrm{mole}$, III, IV, VI, and VII are formed in a one-electron reduction. In the calculation of $n$ the unidentified products are assumed to consume $2 \mathrm{~F} /$ mole.

\section{STRUCTURE DETERMINATION}

Compound III. On the basis of the evidence presented below, compound III was assigned the structure shown above. The formula, $\mathrm{C}_{16} \mathrm{H}_{20} \mathrm{~N}_{2} \mathrm{O}_{2}$, was obtained from elementary analysis and mass spectrometric data; the composition is the same as that of the pinacols suggesting that it is formed, in principle, by a coupling of two one-electron reduction products.

The NMR-spectrum (DMSO-6D) showed a multiplet $(\delta=6.5-7.25$, $\sum \mathrm{H}=4$ ) with at least 18 lines and no prominent singlets indicating the presence of one ortho-substituted benzene ring. Treatment with deuterium oxide showed the presence of four exchangeable protons $\left(\delta=9.0-7.3, \sum \mathrm{H}=2 ; \delta=5.8-5.5\right.$ (doublet), $\sum \mathrm{H}=1 ; \delta=5.3, \sum \mathrm{H}=1$ ) of which three could be acetylated on treatment of III with acetic anhydride in pyridine. No further signals were found in the region where aromatic and ethylenic protons resonate.

The NMR-spectrum further indicated the presence of two methyl groups $(\delta=1.5$ and 2.1), five protons in an unresolved multiplet $(\delta=1.65-2.75)$ 
and a broad signal from one proton at $\delta=4.1-4.35$; the latter became a deformed triplet on addition of $\mathrm{D}_{2} \mathrm{O}$ to the solvent of irradiation or the doublet at $\delta=5.8-5.5$.

The IR-spectrum had a strong absorption at $1590 \mathrm{~cm}^{-1}\left(\mathrm{CHCl}_{3}\right)$ indicative of a strongly hydrogen-bonded carbonyl group; this is substantiated by the NMR-spectrum, in which the singlet at $\delta=2.1$ suggests the presence of a methyl ketone; this is further made plausible by a prominent peak in the mass spectrum at 43 and the difference of 43 between the two highest peaks $(137-94)$. The methyl ketone is neither an acetophenone nor an ordinary $\alpha, \beta$-unsaturated ketone, as it is not polarographically reducible in alkaline solution (Fig. 3).

The low frequency of the carbonyl group in the IR-spectrum is consistent with a $\beta$-dicarbonyl group or a derivative thereof, e.g., a monimine. This is substantiated by the UV-spectrum of III $\left(\lambda_{\max }=308 \mathrm{~nm}, \varepsilon=8900\right.$ at $\mathrm{pH}$ 1 and $\lambda_{\max }=318 \mathrm{~nm}, \varepsilon=11800$ at $\mathrm{pH} \mathrm{13}$ ); although the pinacols (and other derivatives of $\mathrm{I}$ ) absorb in the same region, the extinction coefficient is in acid solution much smaller, whereas the absorption of acetylacetone monimine, $\mathrm{CH}_{3} \mathrm{COCH}=\mathrm{C}\left(\mathrm{NH}_{2}\right) \mathrm{CH}_{3}$, is very similar to that of III $\left(\lambda_{\max }=290 \mathrm{~nm}, \varepsilon=14650\right.$ at $\mathrm{pH} 1 ; \lambda_{\max }=300 \mathrm{~nm}, \varepsilon=14730$ at $\mathrm{pH} 13$ ).

Of the two nitrogens in III one could be titrated in aqueous solution $(\mathrm{pH}=4.75)$, consistent with the presence of an aromatic amine; the other nitrogen atom required perchloric acid in glacial acetic acid for its titration. The low basicity of the latter nitrogen is consistent with its formulation as a $\beta$-dicarbonyl monimine (as enamine); in agreement with that is also the fact that one of the nitrogens is lost as ammonia on treatment with $6 \mathrm{~N}$ hydrochloric acid.

On acetylation of III the two nitrogens are acetylated and the formation of a triacetylderivative VIII suggests that the third acetylated group is an alcohol. The singlet in the NMR-spectrum of III at $\delta=1.5$ suggests a methyl group $\beta$ to the hydroxyl group; the corresponding methyl signals in V, VI, and VII are found at $\delta=1.5$; if this interpretation is correct, the alcohol is tertiary, as the NMR-signal of the methyl group is a singlet.

The presence of a double bond in III is substantiated by the uptake of one mole of hydrogen on catalytic hydrogenation; IR-spectrum of the hydrogenated product (IX) showed the presence of a carbonyl group, and the polarographic non-reducibility of IX and its UV-spectrum indicated that the carbonyl group of IX is not conjugated with a double bond.

The above mentioned data suggest that III consists of two parts, $\mathrm{X}$ and $\mathrm{XI}$, which are joined together in some fashion. Both parts, $\mathrm{X}$ and $\mathrm{XI}$, are remnants from one molecule of $I$; the mass spectrum also suggests an easy fragmentation into two nearly equal parts as the second largest peak is found at $\frac{1}{2} \mathrm{M}+1$.

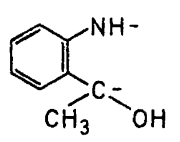

$\mathbf{X}$<smiles>CC(=O)C1CCCCC1N</smiles>

XII

Acta Chem. Scand. 23 (1969) No. 10 
The absence of ethylenic protons and the empirical formula together indicate that X and XI in III are connected through two bonds.

The broad signal in the NMR-spectrum of III at $\delta=4.1-4.35$ collapsed to a deformed triplet on irradiation of the $\mathrm{N}-\mathrm{H}$ doublet at $\delta \sim 5.7$ or on addition of $\mathrm{D}_{2} \mathrm{O}$. This and the chemical shift are consistent with a signal from a proton being $\alpha$ to a nitrogen bearing one proton.

The deformed triplet $(J \sim 3 \mathrm{~Hz})$ results from a coupling to two nonequivalent protons with approximately the same coupling constant, e.g., an equatorial hydrogen coupling with an axial and an equatorial proton at a neighbouring methylene group. Irradiation of the triplet (spectrum of III obtained in pyridine-D5 containing $\mathrm{D}_{2} \mathrm{O}$ ) resulted in a collapse of a triplet at $\delta=1.6$ (integrating $\frac{1}{2} \mathrm{H}$ ) with $J=3.5 \mathrm{~Hz}$ to a doublet with about the same coupling constant; the other half of the signal was buried under the signal from the methyl group at $\delta=1.75$; the distance between the two halves of the signal reveals a coupling constant of $14-15 \mathrm{~Hz}$ which indicates a geminal coupling.

This shows that the nitrogen having one proton is bonded to a carbon having adjacent one carbon with no protons and one having two protons, and that this methylene group is flanked by two carbon atoms having only one hydrogen each. The only formula consistent with this is XII, where $\mathrm{R}$ and $\mathrm{R}^{\prime}$ are $\mathrm{CH}_{3} \mathrm{CO}$ and $\mathrm{NH}_{2}$ or vice versa.

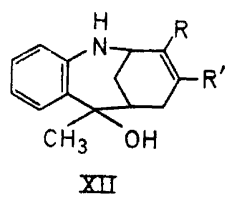

The choice of III rather than the alternative formulation $\left(\mathrm{R}^{\prime}=\mathrm{CH}_{3} \mathrm{CO}\right.$, $\mathrm{R}=\mathrm{NH}_{2}$ ) is based on the following hypothesis for the formation of III.

2<smiles>CC(=O)c1ccccc1N</smiles><smiles>CC(=O)C1=CCC(C(C)(O)c2ccccc2N)C=C1N</smiles>

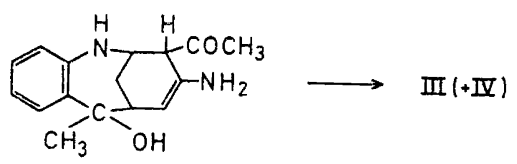

Acta Chem. Scand. 23 (1969) No. 10 
Two radicals (represented above as XIII and XIV) couple to XV whereby an optically active center is created. Each of the two stereoisomers of $X V$ undergo a nucleophilic addition of the aromatic amino group to the $\alpha, \beta$ unsaturated ketone with the formation of III and IV; a somewhat similar nucleophilic addition with resulting ring closure occurs during the formation of one of the reduction products of 1 -acetylnaphthalene in alkaline solution. ${ }^{3}$

The structure of III is confirmed by the NMR-spectrum of the triacetate (VIII) in pyridine-D5; in this the signals from both of the protons in the methylene bridge are visible each as two pairs of triplets at $\delta=1.7$ and $\delta=3.5$ with the geminal coupling constant $14 \mathrm{~Hz}$ and the vicinal ones about $3 \mathrm{~Hz}$. Irradiation of the proton at $\mathrm{C}(2)$ produces a collapse of the triplets into doublets with coupling constants $\sim 3 \mathrm{~Hz}$.

The compounds III and IV have three asymmetric centres. The relative configurations at C-2 and C-6 of III can be deduced from the NMR-spectrum in the following way. The coupling constants (in pyridine-D5 containing $\mathrm{D}_{2} \mathrm{O}$ ) from the proton at $\mathrm{C}-2$ to the protons in the methylene group are both $3-3.5 \mathrm{~Hz}$ which indicates an equatorial-axial $(e-a)$ and an $e-e$ coupling; the proton at $\mathrm{C}-2$ is thus equatorial and the $\mathrm{C}(2)-\mathrm{N}(1)$-bond axial; the ring system is rather stiff and does not allow an interconversion of $a$ to $e$ and vice versa. From the NMR-spectrum of the triacetate (in pyridine-D5) is found that the methylene protons couple to both the bridgehead protons (at C-2 and C-6) with coupling constants $3-3.5 \mathrm{~Hz}$. The proton at C-6 is thus equatorial as it (just as $\mathrm{H}(2)$ ) couples with both the methylene protons with coupling constants corresponding to an $e-a$ and $e-e$ coupling. The protons at $\mathrm{C}-2$ and $\mathrm{C}-6$ are thus cis and the $\mathrm{C}(6)-\mathrm{C}(7)$ bond axial and cis to the $\mathrm{C}(2)-\mathrm{N}(1)$ bond.

Arguments for the configuration at $\mathrm{C}(7)$ relative to that at $\mathrm{C}(6)$ may also be obtained from the NMR-spectra (in DMSO-6D) of III and IV. Whereas the signals from all the aromatic protons of III fall into a single multiplet $(\delta=6.5-7.2)$, the signal of one of the aromatic protons of IV is shifted about $50 \mathrm{~Hz}\left(\delta=7.52\right.$ (quartet), $J_{\mathrm{o}}=7 \mathrm{~Hz}, J_{\mathrm{m}}=2 \mathrm{~Hz}$ ) relative to the three other aromatic protons $(\delta=6.40-6.95)$. Models of III and IV indicate that one of the two configurations has the hydroxyl group near the plane of the phenyl ring, and the NMR-spectrum of IV suggests that it is this isomer which has the hydroxyl group near the plane of the benzene ring and thus cis (with respect to the 7 -membered ring) to the proton at $\mathrm{C}$-6, as the signal from one of the aromatic protons is shifted down-field by the neighbouring hydroxyl group; a similar effect is observed in $\alpha$-naphthol compared to 1 -methylnaphthalene.

The results obtained by the arguments above are substantiated by the positions of the $C(7)$-methyl signals of III and IV. The $C(7)$-methyl group of III would be near to the plane of the benzene ring and thus shielded more strongly by the ring current than the corresponding axial methyl group of IV; the $\mathrm{C}(7)$-methyl groups of III and IV resonate at $\delta=1.51$ and 1.43 , respectively. Calculations according to Johnson and Bovey ${ }^{4}$ indicate an expected difference in chemical shift in the right direction of $0.1 \mathrm{ppm}$, if the protons of the methyl group are assumed to be in their common centre of gravity.

Acta Chem. Scand. 23 (1969) No. 10 
Compound IV has been assigned the structure shown on the basis of the empirical formula $\mathrm{C}_{16} \mathrm{H}_{26} \mathrm{~N}_{2} \mathrm{O}_{2}$ and the similarity between the NMR-, UV-, and IR-spectra of IV and those of III. Also the polarographic behaviour of III and IV is similar. Acetylation of IV with acetic anhydride in pyridine yielded a triacetyl derivative together with some $o$-acetaminoacetophenone.

The structure of the pinacols has not been firmly established. The following approaches were tried:

a) The positions of the signals in the NMR-spectrum of the hydroxyl and methyl groups are indicative of the structure; the D,L-pinacol has its methyl signal at higher and hydroxyl signal at lower field compared to the meso pinacol. This has been rationalized ${ }^{5}$ from considerations of the most favoured conformation, based on hydrogen bond formation. By this token the pinacol, m.p. $183^{\circ}$ (VI) would be the $\mathrm{D}, \mathrm{L}_{-}-$form. However, as the hydrogen bonding may involve the 0 -amino groups as well as the hydroxyl groups, the weight of the argument is diminished.

b) The positions of the absorption bands in the IR-spectra of pinacols have been used ${ }^{6}$ to assign their structures; however, the underlying arguments depend in this case also on the conformations favoured by hydrogen bond formation, and the presence of the amino groups makes also the value of this argument dubious.

c) The rate of the oxidation with lead tetraacetate has been taken as an indication of the structure; the conformation in which the hydroxyl groups of the pinacol are cis is relatively more favoured for the D,L-form than for the meso-pinacol. The amino group is, however, attacked by the reagent, and acetylation of the amino group produced pinacols unreactive towards the reagent.

The results of the present investigation can thus not be used in the standing discussion on whether the coupling of the radicals takes place in the bulk of the solution or near the surface of the electrode, until the structure of the pinacols is determined. The rather small difference in the yield of III and IV has no relevans to the discussion because the product determining step is not the coupling reaction but the intramolecular addition of the amino group to the $\alpha, \beta$-unsaturated ketone.

It has later been shown ${ }^{7}$ that the pinacol m.p. $183^{\circ} \mathrm{C}$ (VI) is the $\mathrm{D}, \mathrm{L}-$ pinacol.

\section{EXPERIMENTAL}

Apparatus. For the electrochemical reductions a fully transistorized potentiostat (Tage Juul Electronics, Copenhagen) capable of delivering $3 \mathrm{~A}$ at $100 \mathrm{~V}$ was used.

The NMR-spectra were recorded on a Varian Associates A-60 or HA-100 spectrometer; tetramethylsilane (TMS) was used as internal standard. The IR-spectra were recorded on a Beckman IR-10 spectrophotometer or on a Perkin-Elmer Infracord; for the UV-spectra a Bausch and Lomb Spectronic 505 was used, and for the mass spectra a Hitachi-Perkin-Elmer RMU-6D.

Reduction of o-aminoacetophenone (I). $1 \mathrm{ml}(1.08 \mathrm{~g})$ of o-aminoacetophenone was reduced at $-1.75 \mathrm{~V}$ (SCE) in a de-aerated, pre-reduced phosphate buffer pH 12 containing $20 \%$ ethanol. During the reduction $\mathrm{pH}$ was kept constant by addition of hydrochloric acid; the reduction consumed $1.25 \mathrm{~F} / \mathrm{mole}$. The reduction completed, the reaction mixture was extracted three times with chloroform which was then dried (potassium car-

Acta Chem. Scand. 23 (1969) No. 10 
bonate) and removed in vacuo. The residue (1.1 g) was dissolved in $\mathrm{CDCl}_{3}$ and the $\mathrm{NMR}$ spectrum recorded; from that the composition of the reaction mixture was found.

Similar reductions were made at other $\mathrm{pH}$; the extractions were always done from alkaline solutions. The results are listed in Table 1.

Reduction of o-aminoacetophenone $(I)$. I (5 ml, $5.35 \mathrm{~g})$ was reduced in $0.1 \mathrm{~N}$ potassium hydroxide containing $20 \%$ alcohol at $-1.85 \mathrm{~V}$ (SCE), $n=1.17$. During the reduction a precipitate, $680 \mathrm{mg}$, was formed which was filtered off; the IR-spectrum and m.p. $183^{\circ}$ proved it to be compound VI ("pinacol-183"). The filtrate was extracted with chloroform which after drying with potassium carbonate was evaporated. TLC on silica with ether-light petrol (3:1) showed the presence of $o$-aminoacetophenone $(I)\left(R_{F}=0.94\right)$, 1-(2'-aminophenyl)ethanol (V) $\left(R_{F}=0.62\right)$, "pinacol-183" VI $\left(R_{F}=0.49\right)$, "pinacol$135^{\circ}$ " VII $\left(R_{F}=0.35\right)$, compound IV $\left(R_{F}=0.19\right)$, compound III $\left(R_{F}=0.15\right)$. The residue was separated on a column of silica with a mixture of ether and light petrol as eluent, starting with a 1:1 mixture and gradually increasing the ether contents; isolated were I $(100 \mathrm{mg}), \mathrm{V}(320 \mathrm{mg})$, VI $(400 \mathrm{mg})$, VII $(500 \mathrm{mg})$, IV (1570 mg), and III (1230 mg).

1-( $2^{\prime}$-Aminophenyl) ethanol $(V)$, m.p. $54-57^{\circ} \mathrm{C}\left(57^{\circ}\right)$. (Found: C 70.40; H 7.90; N 10.20. Calc. for $\mathrm{C}_{8} \mathrm{H}_{11} \mathrm{NO}: \mathrm{C} 70.04 ; \mathrm{H} 8.08 ; \mathrm{N} 10.21$ ). $\mathrm{NMR}$-spectrum $\left(\mathrm{CDCl}_{3}\right): \delta=1.55$ (doublet), $\sum \mathrm{H}=3, J=6.5 \mathrm{~Hz} ; \delta=4.95$ (quartet), $\Sigma \mathrm{H}=1, J=6.5 \mathrm{~Hz}, \delta=6.6-7.3$ (multiplet), $\sum \mathrm{H}=4 ; \delta=2-4.5$, broad signals, $\sum \mathrm{H}=2+1$.

Compound $V$ was acetylated with acetic anhydride to 1-(2'-acetaminophenyl)ethanol, m.p. $78^{\circ}$ (ethanol). (Found: C 67.0; $\mathrm{H} \mathrm{7.3;} \mathrm{N} \mathrm{7.7.} \mathrm{Calc.} \mathrm{for} \mathrm{C}_{10} \mathrm{H}_{13} \mathrm{NO}_{2}$ : C 67.02: H 7.31; N 7.82).

The hydroxyl group of the acetate was benzoylated, m.p. $132-134^{\circ} \mathrm{C}$ (ethanol). (Found: $\mathrm{C} 71.7 ; \mathrm{H} 6.0 ; \mathrm{N}$ 5.0. Calc. for $\mathrm{C}_{17} \mathrm{H}_{17} \mathrm{NO}_{3}$ : $\mathrm{C} 72.07 ; \mathrm{H} 6.05 ; \mathrm{N} 4.94$ ). Nitrobenzoate of acetate, m.p. $141-143^{\circ} \mathrm{C}$ (ethanol). (Found: $\mathrm{C} \mathrm{61.7;} \mathrm{H} \mathrm{4.7;} \mathrm{N} \mathrm{8.6.} \mathrm{Calc.} \mathrm{for} \mathrm{C}_{17} \mathrm{H}_{16} \mathrm{~N}_{2} \mathrm{O}_{5}$ : C 62.19; H 4.91; N 8.53).

2,3-Bis (2'-aminophenyl)-butane-2,3-diol (VI), m.p. $183^{\circ} \mathrm{C}$ (benzene). (Found: C 70.65; $\mathrm{H}$ 7.58; $\mathrm{N} 10.32$. Calc. for $\mathrm{C}_{16} \mathrm{H}_{20} \mathrm{NO}_{2}$ : C 70.56; $\mathrm{H} 7.40 ; \mathrm{N} \mathrm{10.29)}$. NMR-spectrum $\left(\mathrm{CDCl}_{3}\right)$ : $\delta=1.37$ (singlet), $\sum \mathrm{H}=3 ; \delta=5.35$ (broad singlet), $\sum \mathrm{H}=3 ; \delta=6.6-7.3$ (multiplet), $\sum \mathrm{H}=4$. IR-spectrum $\left(5 \% \mathrm{CHCl}_{3}, \mathrm{~cm}^{-1}\right): 3440(\mathrm{~m}), 3340(\mathrm{~s}), 3005(\mathrm{~s}), 1618(\mathrm{~s}), 1590(\mathrm{~m})$, $1500(\mathrm{~s}), 1458(\mathrm{~s}), 1387(\mathrm{~m}), 1299(\mathrm{~m}), 1235(\mathrm{~m}), 1100(\mathrm{~m}), 1055(\mathrm{~s})$. UV-spectrum: pH 1, $\lambda_{\text {shoulder }}=256 \mathrm{~nm}(\varepsilon=1600), \mathrm{pH} 14, \lambda_{\max }=301 \mathrm{~nm},(\varepsilon=9130)$.

2,3-Bis (2'-aminophenyl)-butane-2,3-diol (VII), m.p. $134-136^{\circ} \mathrm{C}$ (ethanol). (Found: C 70.62; $\mathrm{H} 7.33 ; \mathrm{N}$ 10.24. Calc. for $\mathrm{C}_{16} \mathrm{H}_{20} \mathrm{~N}_{2} \mathrm{O}_{2}$ : C 70.56; $\mathrm{H} 7.40 ; \mathrm{N} \mathrm{10.29).} \mathrm{NMR-spectrum}$ $\left(\mathrm{CDCl}_{3}\right): \delta=1.66$ (singlet), $\sum \mathrm{H}=3 ; \delta=4.6$ (broad singlet) $\sum \mathrm{H}=3 ; \delta=6.45-7.2$ (multiplet) $\sum \mathrm{H}=4$. IR-spectrum $\left(5 \% \mathrm{CHCl}_{3}, \mathrm{~cm}^{-1}\right): 3420(\mathrm{~m}), 3330(\mathrm{~m}), 3020(\mathrm{~s}), 1618(\mathrm{~s}), 1500(\mathrm{~m})$, $1456(\mathrm{~s}), 1235(\mathrm{~s}), 1205(\mathrm{~m}), 1050(\mathrm{~s})$. UV-spectrum: pH $1, \lambda_{\max }=258 \mathrm{~nm},(\varepsilon=400) ; \mathrm{pH} 13$, $\lambda_{\max }=299 \mathrm{~nm},(\varepsilon=4600)$.

3-Acetyl-4-amino-7-hydroxy-7-methyl-2,6-methano-2,5,6,7-tetrahydro-1(1H)-benzazonine (IV), m.p. $165-167^{\circ} \mathrm{C}$ (ethanol). (Found: C 70.53; $\mathrm{H} 7.35 ; \mathrm{N} \mathrm{10.19}$. Calc. for $\mathrm{C}_{16} \mathrm{H}_{20} \mathrm{~N}_{2} \mathrm{O}_{2}$ : C 70.56; H 7.40; N 10.29). NMR-spectrum (DMSO-D6): $\delta=1.43$ (singlet), $\sum \mathrm{H}=3$; $\delta=2.1$ (singlet), $\sum H=3 ; \delta=1.50-2.45$ (multiplet), $\sum H=5 ; \delta=4.0-4.3$ (broad signal), $\sum \mathrm{H}=1 ; \delta=4.8$ (singlet), $\sum \mathrm{H}=1 ; \delta=5.3$ (broad doublet, $J=6 \mathrm{~Hz}$ ), $\sum \mathrm{H}=1 ; \delta=6.40-6.95$ (multiplet), $\Sigma \mathrm{H}=3 ; \delta=7.52$ (quartet, $J_{0}=7 \mathrm{~Hz}, J_{\mathrm{m}}=2 \mathrm{~Hz}$ ), $\sum \mathrm{H}=1$. IR-spectrum $\left(\mathrm{KBr}, \mathrm{cm}^{-1}\right): 3350(\mathrm{~s}), 3200(\mathrm{~m}), 2880(\mathrm{~m}), 1575(\mathrm{~s}), 1470(\mathrm{~s}), 1250(\mathrm{~s}), 1205(\mathrm{~m}), 1038(\mathrm{~m})$, 945(m), 905(m), 765(m), 755(s). UV-spectrum: pH 1, $\lambda_{\max }=298 \mathrm{~nm}(\varepsilon=3000), \mathrm{pH} 13$, $\lambda_{\text {max }}=317 \mathrm{~nm}(\varepsilon=10800)$.

3-Acetyl-4-amino-7-hydroxy-7-methyl-2,6-methano-2,5,6,7-tetrahydro-1(1H)-benzazo-

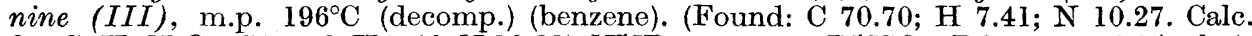
for $\mathrm{C}_{16} \mathrm{H}_{20} \mathrm{~N}_{2} \mathrm{O}_{2}$ : C 70.56; $\mathrm{H} 7.40 ; \mathrm{N} 10.29$ ). NMR-spectrum (DMSO-D6): $\delta=1.51$ (singlet), $\sum \mathrm{H}=3 ; \quad \delta=2.1 \quad$ (singlet), $\sum \mathrm{H}=3 ; \delta=1.65-2.75 \quad$ (multiplet), $\sum \mathrm{H}=5 ; \delta=4.1-4.35$ (broad signal), $\sum \mathrm{H}=1 ; \delta=5.3$ (singlet), $\sum \mathrm{H}=1 ; \delta=5.65$ (broad dublet, $J=6 \mathrm{~Hz}$ ), $\sum \mathrm{H}=1 ; \delta=6.5-7.25$ (multiplet), $\sum \mathrm{H}=4 ; \delta=7.3-9.0$ (very broad signal), $\sum \mathrm{H}=2 . \mathrm{On}$ addition of $\mathrm{D}_{2} \mathrm{O}$ the signals at $\delta=7.3-9.0,5.65$, and 5.3 disappeared, whereas the broad signal at $\delta=4.1-4.35$ became a deformed triplet. IR-spectrum $\left(\mathrm{KBr}, \mathrm{cm}^{-1}\right): 3290(\mathrm{~s})$, $3140(\mathrm{~m}), 2925(\mathrm{~m}), 2895(\mathrm{~m}), 1590(\mathrm{~s}), 1470(\mathrm{~s}), 1405(\mathrm{~s}), 1250(\mathrm{~m}), 940(\mathrm{~m}), 920(\mathrm{~m}), 780(\mathrm{~m})$, $750(\mathrm{~m})$. UV-spectrum: $\mathrm{pH} 1, \lambda_{\max }=308 \mathrm{~nm}(\varepsilon=8900) ; \mathrm{pH}=13, \lambda_{\max }=318 \mathrm{~nm}(\varepsilon=11800)$. Mass spectrum $(m / e(\%)): 18(9), 28(43), 43(87), 65(26), 77(28), 92(19), 94(100), 105$ (34), $118(38), 120(32), 136(62), 137(92), 239(11), 254(14), 272(6) . \mathrm{p} K_{1}$ of III=4.75, $\mathrm{p} K_{2}<1$.

Acta Chem. Scand. 23 (1969) No. 10 
Acetylation of III. Compound III ( $0.935 \mathrm{~g})$ was dissolved in $5 \mathrm{ml}$ of acetic anhydride and $5 \mathrm{ml}$ of pyridine and heated on a steam bath for $6 \mathrm{~h}$. The cooled reaction mixture was then poured into $10 \mathrm{ml} 4 \mathrm{~N}$ hydrochloric acid and extracted with chloroform. The organic layer was washed with an aqueous solution of sodium carbonate, dried (potassium carbonate), and the solvent removed in vacuo. On addition of ether a precipitate $\left(160 \mathrm{mg}\right.$ ) was obtained, m.p. $254-256^{\circ} \mathrm{C}$ (ethanol). (Found: C 66.51; H 6.68; N 7.17. Calc. for $\mathrm{C}_{22} \mathrm{H}_{26} \mathrm{~N}_{2} \mathrm{O}_{5}$ : C 66.32; $\mathrm{H} 6.58 ; \mathrm{N} 7.03$ ). NMR-spectrum (DMSO-D6): $\delta=1.25-$ 1.55 (multiplet), $\sum \mathrm{H}=1 ; \delta=1.67$ (singlet), $\sum \mathrm{H}=3 ; \delta=1.86$ (singlet), $\sum \mathrm{H}=3 ; \delta=1.87$ (singlet), $\sum \mathrm{H}=3 ; \delta=2.0-2.35$ (multiplet), $\sum \mathrm{H}=1 ; \delta=2.18$ (singlet), $\sum \mathrm{H}=3 ; \delta=2.6-$ 3.1 (multiplet), $\sum \mathrm{H}=3 ; \delta=3.30$ (singlet), $\sum \mathrm{H}=3 ; \delta=4.94$ (singlet), $\Sigma \mathrm{H}=1 ; \delta=5.6$ (broad signal), $\sum \mathrm{H}=1 ; \delta=6.9-7.5$ (multiplet), $\sum \mathrm{H}=4$. IR-spectrum: $\left(\mathrm{KBr}, \mathrm{cm}^{-1}\right)$ $3340(\mathrm{~s}), 2950(\mathrm{~m}), 1700(\mathrm{~s}), 1630(\mathrm{~s}), 1580(\mathrm{~s}), 1390(\mathrm{~s}), 1220(\mathrm{~s}), 935(\mathrm{~m}), 768(\mathrm{~m})$. UV -spectrum $\left(\mathrm{CHCl}_{3}, \mathrm{~cm}^{-1}\right): \lambda_{\max }=309 \mathrm{~nm}(\varepsilon=10400)$.

Besides the triacetate of III the only other compound identified from the reaction mixture was 0 -acetaminoacetophenone $(80 \mathrm{mg})$, which was obtained by chromatography of the filtrate on silica with ether as eluent.

Acetylation of IV. Compound IV $(350 \mathrm{mg})$ was acetylated and the products extracted as above. The reaction mixture was separated on a column of silica with ether as eluent. Besides o-acetaminoacetophenone $(15 \mathrm{mg})$ was isolated a compound $(30 \mathrm{mg}) \mathrm{m} . \mathrm{p} .258$ $260^{\circ} \mathrm{C}$ (ethanol) which from the empirical formula was suggested to be the triacetate of IV. (Found: C 66.70; $\mathrm{H} \mathrm{7.00;} \mathrm{N} 7.32$. Calc. for $\mathrm{C}_{22} \mathrm{H}_{28} \mathrm{~N}_{2} \mathrm{O}_{5}$ : C 66.32; $\mathrm{H} \mathrm{6.58;} \mathrm{N} \mathrm{7.03).}$ IR-spectrum $\left(\mathrm{KBr}, \mathrm{cm}^{-1}\right) 3420(\mathrm{~s}), 2950(\mathrm{~m}), 1690(\mathrm{~s}), 1640(\mathrm{~s}), 1575(\mathrm{~s}), 1450(\mathrm{~s}), 1360(\mathrm{~s})$, $1210(\mathrm{~s}), 975(\mathrm{~m}), 910(\mathrm{~m}), 778(\mathrm{~s})$.

Acknowledgment. Thanks are due to Dr. Christian Pedersen, The Technical University, Copenhagen, for the recording of the NMR-spectra on Varian HA-100 spectrometer, and to Dr. Martin Ettlinger, US Army Natick Laboratories, Natick, Massachusetts 01760, USA, for valuable discussions.

\section{REFERENCES}

1. Lund, H. Acta Chem. Scand. 13 (1959) 249.

2. Elving, P. J. and Leone, J. T. J. Am. Chem. Soc. 80 (1958) 1021.

3. Grimshaw, J. and Rea, E. J. F. J. Chem. Soc. 19672628.

4. Johnson, C. E. and Bovey, F. A. J. Chem. Phys. 29 (1958) 1012.

5. Stocker, J. H. and Jenevein, R. M. J. Org. Chem. 33 (1968) 294.

6. Mosher, W. A. and Heindel, N. D. J. Org. Chem. 28 (1963) 2154.

7. Thomsen, A. D. and Lund, H. Acta Chem. Scand. 23 (1969) 3582.

Received April 25, 1969. 